\title{
Glycogen Storage Disease Type III-Cori's Disease: A Case Report and Review Literature
}

\author{
SAYEEDAANWAR, AKM MATIUR RAHAMAN, ABDUL MATIN, DIPA SAHA, MALIHARASHID
}

\begin{abstract}
Introduction
Glycogen-storage disease (GSD) type III (GSD III) is an autosomal recessive inborn error of metabolism caused by loss of function mutations of the glycogen debranching enzyme (Amylo-1,6-glucosidase [AGL]) gene, which is located at chromosome band 1p21.2.1 GSD III is characterized by the storage of structurally abnormal glycogen, termed limit dextrin, in both liver, skeletal and cardiac muscle with greater variability in resultant organ dysfunction. ${ }^{2}$ Clinical manifestations are usually due to decreased hepatic glycogenolysis and occasionally due to a myopathy associated with an increase in muscle glycogen. Patients with GSD are usually diagnosed in infancy or early childhood with hypoglycemia, hepatomegaly, poor physical growth, and a deranged biochemical profile. The reported case of GSD type III had predominantly liver involvement. There were very few reports on Cori,s disease. Objective of reporting this case is to evaluate and as no cases of glycogen storage disease type IIIcori's disease had been reported from Bangladesh till now.
\end{abstract}

It is important to recognize the condition early in order to manage the condition effectively and to minimize the morbidity and mortality.

\section{Case report}

A three-years-old female child was admitted with progressive abdominal distension since her 5 months of age. She was only issue of consanguineous parents. She had recurrent episodes of loose stools and occasional low grade fever since her early infancy. For these illnesses she was treated by local physician

1. Professor, Department of pediatrics, Dhaka Medical college Hospital

2. Professor, Department of pediatrics, Dhaka Medical college Hospital

3. Assistant Professor, Department of pediatrics, Dhaka Medical college Hospital

4. Assistant professor, Department of pediatrics, Bashundhara Addin medical College Hospital

5. Indoor Medical officer, Department of pediatrics, Dhaka Medical college Hospital

Correspondence: Prof. Sayeeda Anwar, E-mail: sayeeda.anwar 01@gmail.com for several times but parents were not concerned about abdominal distension. Three months before of admission in Dhaka medical College Hospital, she suddenly developed high grade fever associated with upper abdominal pain and yellowish coloration of sclera for 7 days. Along with this she had also haematemesis and malaena. Then admitted in Shahid Ziaur Rahman Medical College Hospital, Bogra and was diagnosed as a case of fulminant hepatic failure .With all supportive managements she improved within 10 days. Mother had bad obstetric history with one still birth and one abortion.

On examination patient had doll face. She was well alert, mildly pale, undernourished (Wt-10 kg, WAZ: 3.8) and severely stunted (Ht-80cm, HAZ: - $3.75 \mathrm{SD}$ ). Abdomen was distended with huge hepatomegaly. Other systems were normal.

Her laboratory findings revealed mild normocytic normochromic anemia, ALT: 627U/L but other liver function tests were normal. Lipid profile showed high Cholesterol 237mg/dl, LDL 215 mg/dl, TG 259 mg/dl, HDL $34 \mathrm{mg} / \mathrm{dl}$, Serum creatinine $0.5 \mathrm{mg} / \mathrm{dl}$. Serum electrolyte $\mathrm{Na}^{+} 137 \mathrm{mmol} / \mathrm{L}, \mathrm{K}^{+} 3.8 \mathrm{mmol} / \mathrm{L}, \mathrm{Cl}^{-}$ $100 \mathrm{mmol} / \mathrm{L}, \mathrm{CO}_{2} 26 \mathrm{mmol} / \mathrm{L}$. Serum Alfa feto protein $30 \mathrm{ng} / \mathrm{dl} \quad(<15 \mathrm{ng} / \mathrm{dl})$. Slit lamp examination Normal. Serum Ceruloplasmin: $27 \mathrm{mg} / \mathrm{dl} \quad(22-45 \mathrm{mg} / \mathrm{dl})$, Viral marker: HBsAg, Anti HCV, Anti HAV, Anti HEV. Fasting blood sugar $3.4 \mathrm{mmol} / \mathrm{L}, 2$ hours after breakfast $6.8 \mathrm{mmol} / \mathrm{L}$, S.amonia $82 \mathrm{micromol} / \mathrm{L}$, S. lactate $1.5 \mathrm{mmol} / \mathrm{l}$, urinary ketone absent, $\mathrm{ABG} \mathrm{PH} 7.34, \mathrm{P}_{\mathrm{CO} 2}$ $40 \mathrm{mmol} / \mathrm{L}, \mathrm{P}_{\mathrm{O} 2} 54.5 \mathrm{mmol} / \mathrm{L}, \mathrm{HCO} 321.7 \mathrm{mmol} / \mathrm{L}$, CPK $25 \mathrm{U} / \mathrm{L}$ (5-130 U/L), ECG and echocardiography was normal. USG of Abdomen -Liver is grossly enlarged in size with slight coarse echo texture

The child was suspected to have glycogen storage disorder based on findings of gradual abdominal distension, round face, massive hepatomegaly, hypertriglyceridemia, hypercholesterolemia and abnormal liver enzymes, slight coarse echo texture of liver in USG and hugely enlarged in size with coarse and hyper dense parenchyma in CT scan (Fig.-2). 


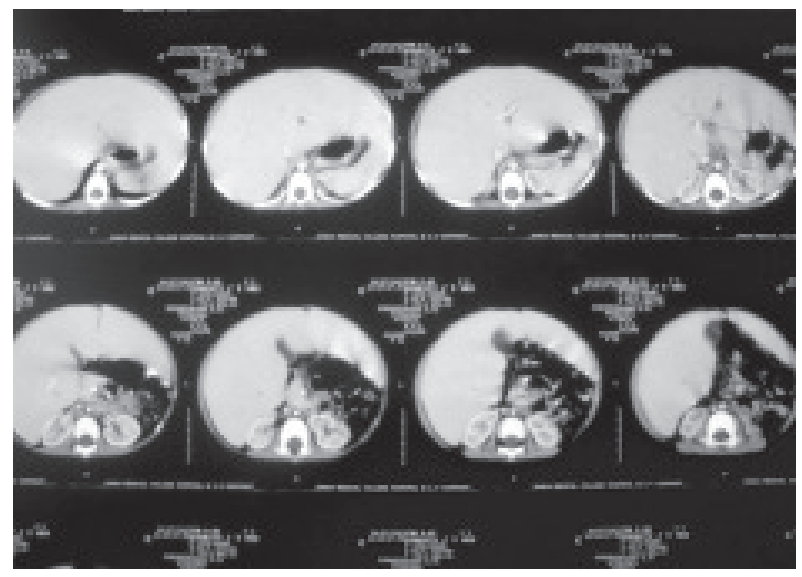

Fig.-2: CT scan of abdomen showed liver is hugely enlarged in size with coarse \& hyper dense parenchyma. Left lobe and quadrate lobe is also enlarged . No obvious focal lesion. Suggestive of Storage disease.

She was diagnosed GSD type III based on liver histology. Liver histology with hematoxylin-eosin stained reaction showed hepatocytes with vacuolated cytoplasm and central nuclei, PAS stains showed accumulation of glycogen within the hepatocytes. Portal areas showed inflammatory infiltrate and fibrosis (Fig. 3). The above findings were consistent with glycogen storage disease type III.

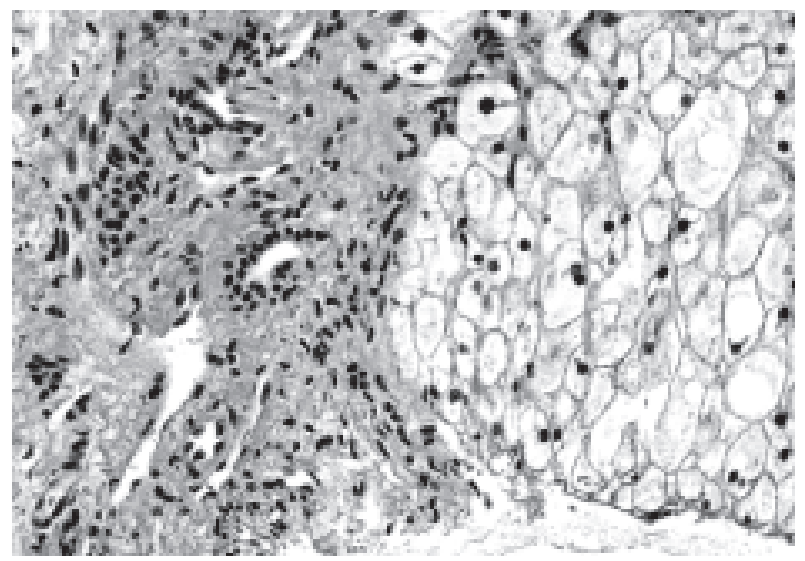

Fig.-3: Swollen hepatocyte, lobular architecture is preserved with periportal fibrosis.

The patient was put on a high protein-(3gm/ $/ \mathrm{kg})$ egg, milk, fish, chicken and frequent round the clock carbohydrate diet -bread, rice, uncooked corn starch (Chira, Muri, Khoi), low fatty diet, Vit C, Vit A. B complex $\mathrm{Ca}$, Iron supplementation and advised to avoid sugar, gur, honey, soft drinks, red meat, egg yolk, fried meal, coconut, prawn and discharged. The child did not come for further follow up.

\section{Discussion}

GSD type III is an autosomal recessive disorder, protean in its manifestations. It is a metabolic disease in which glycogen with very short outer arms, the so called limit dextrin, is stored in liver or muscle because of a deficiency of debranching enzyme ${ }^{1}$ Approximately $85 \%$ of patients are GDE deficient in both liver and muscle (type IIla) and $15 \%$ of patients have GDE (glycogen Debranching Enzyme) absent in liver but retained in muscle (type IIIb). It is presents in early childhood and has an incidence of 1:50,000 to $1: 70,000 .^{2}$ Gross hepatomegaly, hypoglycemia, seizures and growth retardation are the main presentations. The case also had similar presentation. Majority of the cases with hepatic involvement present with protruded abdomen because of gross hepatomegaly and also have raised serum aminases and serum cholesterol. Liver, skeletal muscle and heart are the main organs involved in various levels of severity. In the present case, hepatic involvement was predominant with no cardiac and skeletal muscle involvement. Cerebral development is usually normal, and there is truncal obesity and a doll like face. There was no history suggestive of hypoglycemic episodes in the present case. Hypoglycemia is less frequent in GSD III as compared to type I. The serum concentration of uric acid, lactate and ketones are normal. In majority of the reported cases liver pathology has been predominant.

In the myopathic form, slight to severe impairment of muscle function and slowly progressive distal muscular wasting develops during later childhood or adulthood. ${ }^{3}$ Accumulation of glycogen in heart may lead to moderate cardiomegaly with nonspecific ECG changes, although rarely accompanied by clinical symptoms. ${ }^{4}$

The liver histopathology in type III GSD is very similar in appearance to that seen in type I GSD; universal distension of hepatocytes producing a mosaic architecture and periportal nuclear hyperglycogenation is prominent. The notable distinctions from type I glycogenosis are the presence of fibrous septa formation and the paucity of fat. ${ }^{5}$

GDE is an unusual protein because of its two independent catalytic activities; 1,4-alpha-d-glucan 4alpha-d-glycosyltransferase and AGD, with separate active sites on a single polypeptide. ${ }^{6}$

GSD IIla and IIIb are allelic disorders. DNA mutation analysis can help confirm the diagnosis and provide 
information to predict GSD III subtype, carrier testing, and prenatal or pre-implantation genetic diagnosis. Mutations causing GSD IIla are scattered throughout the AGL gene and are associated with considerable allelic heterogeneity. All mutation types, including missense, nonsense, splice site, small frame shift deletions and insertions, and large gene deletions and duplications, have been described in the AGL gene. Most mutations are specific to individual families although there are some common mutations associated with specific ethnic backgrounds. Patient was diagnosed GSD type III based on liver histology. Enzyme analysis and DNA mutation could not be done.

Treatment is mainly dietary. The advocated treatment for GSD type III comprises frequent high protein feedings during the day and a high protein snack at night; energy is distributed as $45 \%$ carbohydrates, $25 \%$ protein and $30 \%$ fat. ${ }^{7}$ Carbohydrates should be given frequently round the clock when the patient is young. Uncooked corn starch therapy can be started in the older child and is very useful. ${ }^{8}$ Gastric drip feeding at night may be introduced in the infant if hypoglycemia is a problem. ${ }^{9}$ Corn starch therapy can be started in the older child and is useful. ${ }^{10}$ Diet should be rich in high class proteins because some aminoacids serve as substrate for gluconeogenesis. ${ }^{11}$ Fat intake should be reduced.

The cirrhosis found in some patients is of a mild degree and does not have a significant impact on the course of the disease. Patients with cardiac involvement (ie, patients with GSD type IIla), regardless of their age, have a risk of cardiovascular disturbances resulting as a complication of their GSD.

Follow up plan is blood glucose and ketones, routinely. Yearly: height and weight to monitor growth; USG, LFTs, CK, lipid profile, ECG and Echocardiogram to monitor for cardiomyopathy; Progressive liver disease with liver fibrosis occurs throughout life. In some cases, cirrhosis and hepatocellular carcinoma may occur. Prognosis is guarded but in cirrhotic case outcome is very poor. Prenatal diagnosis has been performed by enzyme analysis of amniotic fluid fibroblasts or chorionic villi. ${ }^{8}$

\section{References}

1. Goldberg T, Slonim AE. Nutrition therapy for hepatic glycogen storage disease. J Am Diet Assoc. 1993;12:1423-30.

2. Haagsma EB, Smit GP, Niezen Koning KE, Gouw AS, Meerman L, Slooff MzJ. Type IIIb glycogen storage disease associated with endstage cirrhosis and hepatocellular carcinoma. Hepatology. 1997;25:537-40

3. Dunger DB, Leonard JV, Preece MA. Pattern of growth in the Hepatic Glycogenesis. Arch Dis Child. 1984;59:657-60.

4. Moses SW, Gadoth N, Bashan N, BenDavid E, Slonin A, Wanderman KL. Neuromuscular involvement in glycogen storage disease type III. Acta Pediatr Scand. 1986;75:289-96.

5. McAdams AJ, Hug G, Bove KE. Glycogen storage disease, types I to $\mathrm{X}$. Criteria for morphologic diagnosis. Hum Pathol. 1974;5: 463-87.

6. Gremse DA, Bucurales JC, Balistreri WF. Efficacy of corn starch therapy in type III glycogen storage disease. Am J Clin Nutr. 1990; 52:67174.

7. Shen JJ, Chen YT. Molecular characterization of glycogen storage disease type III. Curr Mol Med. 2002;2:167-75.

8. Van Diggelen OP, Janose HC, Smit GPA. Debranching enzyme in fibroblasts, amniotic fluid cells and chorionic villi: pre-andpost-natal diagnosis of glycogenosis type III. Clin Chim Acta. 1985;149:129-34.

9. Fernandes J, Leonard JV, Moses SW. Glycogen storage disease: Recommendations for treatment. Eur J Pediatr. 1988;147:226-28.

10. Gremse DA, Bucurales JC, Balistreri WF. Efficacy of corn starch therapy in type III glycogen storage disease. Am J Clin Nutr. 1990; 52: 67174.

11. Slonin AE, Coleman RA, Moses WS. Myopathy and growth failure in debrancher enzyme deficiency: Improvement with high protein nocturnal entral therapy. J Pediatr. 1984;105: 906-11. 